\title{
The effect of sulfate half-ester groups on cellulose nanocrystal periodate oxidation
}

\author{
Saül Llàcer Navarro • Koyuru Nakayama • Alexander Idström • \\ Lars Evenäs · Anna Ström • Tiina Nypelö (i)
}

Received: 12 May 2021/Accepted: 24 July 2021/Published online: 17 August 2021

(C) The Author(s) 2021

\begin{abstract}
Periodate oxidation introduces aldehyde functionality to cellulose. The use of dialdehyde cellulose has been demonstrated for crosslinking and as a chemical intermediate towards functionalized cellulose. Commercially available cellulose nanocrystals (CNCs) typically carry a surface sulfate half-ester functionality, which results from their manufacture via sulfuric acid hydrolysis and subsequent esterification. The sulfate half-ester group is a bulky group carrying a net negative charge above $\mathrm{pH} 2$ that modifies the colloidal and electro-chemical properties of the CNCs. Periodate oxidation is regioselective to the bond between carbons in positions 2 and 3 in the anhydroglucose unit while the sulfate half-ester groups are mostly considered to be located in carbon in position 6 . This regioselectivity could be the reason why the role played by the sulfate half-ester group on modification
\end{abstract}

Supplementary Information The online version contains supplementary material available at https://doi.org/10.1007/ s10570-021-04115-y.

S. Llàcer Navarro · K. Nakayama ·

A. Idström · L. Evenäs · A. Ström · T. Nypelö $(\bowtie)$

Department of Chemistry and Chemical Engineering,

Chalmers University of Technology, 41296 Gothenburg,

Sweden

e-mail: tiina.nypelo@chalmers.se

S. Llàcer Navarro · K. Nakayama ·

L. Evenäs · T. Nypelö

Wallenberg Wood Science Center, Chalmers University

of Technology, 41296 Gothenburg, Sweden by periodate oxidation has not previously been elucidated. Here, the influence of the sulfate half-ester on the oxidation of CNCs, which is shown to steer the oxidation kinetics and the properties of the resulting materials, is studied. Conventional physicochemical analysis of the oxidant consumption is accompanied by elemental analysis, Fourier-transform infrared, X-ray photoelectron and solid-state nuclear magnetic resonance spectroscopy, and wide-angle $\mathrm{x}$-ray scattering analyses; the zeta potential is used to characterize the colloidal properties of the suspensions and atomic force microscopy for determining particle dimensions. The presence of the sulfate half-ester group decreases the rate of oxidation. However, the content of the sulfate half-ester groups decreases when degree of oxidation reaches approx. 50\%. We demonstrate that the $\mathrm{CNC}$ surfaces are affected by the oxidation beyond the $\mathrm{C} 2-\mathrm{C} 3$ bond cleavage: insight into the kinetics of the oxidation process is a prerequisite for optimizing CNC oxidation.

Keywords Cellulose nanocrystals $\cdot$ Periodate oxidation $\cdot$ Sulfate half-esters

\section{Introduction}

It is only recently that native cellulose has been accessible to nanotechnology due to the 
heterogeneous morphology and the millimeter size of wood fibers. The development of the liberation of nanosized colloidal cellulose nanocrystals (CNCs) from cellulosic materials via hydrolysis with mineral acids, has transformed these entities into bio-based nanoparticles (Kontturi et al. 2018). Sulfuric acid hydrolysis is employed to digest the most accessible, amorphous cellulose chain arrangements, leading to the liberation of the remaining, more ordered, segments into CNCs. Hydrolysis with sulfuric acid leads to the simultaneous esterification of the CNC surfaces with sulfate half-ester groups (Eyley and Thielemans 2014). The salt-form (i.e., $\mathrm{Na}^{+}{ }_{-} \mathrm{CNCs}, \mathrm{K}^{+}$-CNCs) allow drying and redispersing. $\mathrm{CNCs}$ have been demonstrated as being suitable for use in nanocomposites, biomedical devices, emulsions and foams, and as rheology modifiers (Sinha et al. 2015; Vanderfleet and Cranston 2021).

Chemical modification for the functionalization of CNCs utilizes the hydroxyl, sulfate half-ester groups, or the reducing end group (Eyley and Thielemans 2014; Zoppe et al. 2020). The removal of the sulfate groups is one way of modifying the CNCs (Jordan et al. 2019). By far the majority of modifications make use of the hydroxyl groups of cellulose.

Oxidation is a common reaction for modifying CNCs. Periodate oxidation cleaves the bond in the anhydroglucose unit (AGU) between carbons in positions 2 and 3 (C2 and $\mathrm{C} 3$ ) transforming them into aldehydes and further hydrated aldehydes in water (Nypelö et al. 2021). The aldehyde groups can react with vicinal hydroxyls to form hemiacetals or hemialdals (Sulaeva et al. 2015). Moreover, further oxidation or reduction leads to alcohol and carboxyl derivates (Larsson et al. 2014; Liimatainen et al. 2012; Nypelö et al. 2018), which are used for modifying the thermal and mechanical properties of cellulose materials (López Durán et al. 2018; Larsson et al. 2014). The periodate oxidation of crystalline cellulose typically leads to degradation alongside the chemical modification (Sun et al. 2015) and reduces the crystal size or degree of polymerization. It has been reported that the crystallinity of cellulose decreases with oxidation (Liu et al. 2012). Elevated temperature accelerates oxidation leading to, not only an increase in the reaction rate, but also accelerated degradation (Liu et al. 2012). Degradation of the crystalline regions has been proposed as occurring heterogeneously, leading to a local loss of order and isolated oxidized domains (Kim et al. 2000). The highly-ordered regions (crystalline) in cellulose are reported to be affected already at low degree of oxidation (DO) (Potthast et al. 2007, 2009). Peeling off from the surface layer has been demonstrated as being a result of oxidation, being evidenced by altered CNC dimensions (Conley et al. 2017) and nuclear magnetic resonance (NMR) spectroscopy analysis (Koso et al. 2020). The determining factor of the oxidation rate has been found to be the overall crystallinity (Siller et al. 2015). The hierarchy (fiber, fibril, crystal) of the starting materials does, however, also play a role here (Yuldoshov et al. 2016).

The sulfate half-ester groups provide colloidal stability to the CNC suspensions because their deprotonation leads to the presence of a negative charge. We hypothesize that the groups may affect the oxidation reaction as well. The effect of sulfate half-ester group is suggested to be due to repulsion between the charged sulfate half-ester group and the negatively charged periodate ion. The bulky sulfate half-ester group may also be a steric hindrance to the periodate ion in accessing the oxidizable diols. The effect of sulfate half-ester groups on the periodate oxidation of $\mathrm{CNCs}$ are elucidated; furthermore, we investigated how the initial content of sulfate half-ester groups affects the properties of the oxidized CNC product. Knowledge of the effect of the sulfate half-ester groups on CNCs and their oxidative modification is pivotal to optimizing the modification of the industrial $\mathrm{CNC}$ grades and their employment in nanotechnology.

\section{Experimental}

Materials

CNCs (cellulose sulfate sodium salt) were purchased from Celluforce (Canada). Cellulose is comprised of anhydroglucose units (AGUs) (Fig. 1a) and the cellulose sulfate contains a fraction AGUs with a sulfate half-ester substitute (Fig. 1b). Sodium periodate, hydroxylamine hydrochloride, glycerol, sodium chloride, sodium acetate, acetic acid, potassium bromide, and hydrochloric acid were purchased from Sigma-Aldrich and used without further purification. MilliQ-water (resistivity $=18.2 \Omega^{-1} \mathrm{~cm}^{-1}$ at $25^{\circ} \mathrm{C}$ ) 
Fig. 1 The schematic structure of a AGU b AGU with a sulfate half-ester (blue) and c) 2,3dialdehyde-AGU. The aldehyde groups are marked in red

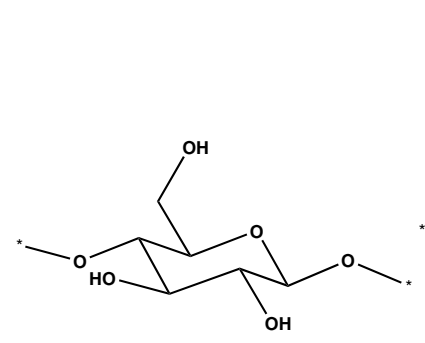

(a)

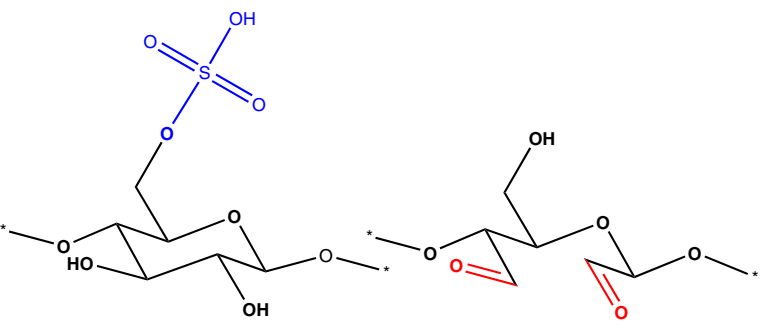

(b)

(c) was obtained from the Millipore water purification system and used unless otherwise stated.

The CNCs were desulfated via acid catalyzed approach. The method is known not to lead to complete desulfation and is facile and scaleable (Jiang et al. 2010). Desulfation of CNCs was performed so that the CNC powder was dispersed in MilliQ-water to a concentration of $5 \mathrm{wt} \%$, after which $12 \mathrm{M} \mathrm{HCl}$ was added to obtain an acid concentration of $1.8 \mathrm{M}$. The dispersion was heated and stirred at $90{ }^{\circ} \mathrm{C}$ with reflux for $2 \mathrm{~h}$. The suspension was dialyzed until the $\mathrm{pH}$ of the dialysate was the same as the deionized water used for the dialysis. A spectrapore membrane with a cut off of 12-14,000 $\mathrm{g} \mathrm{mol}^{-1}$ (VWR, Sweden), was used for dialysis. The desulfated CNC grade is henceforth referred to as desulfCNC.

A procedure from Dash et al. (2013) was adapted for oxidation, whereby the CNCs were oxidized using sodium metaperiodate to a $\mathrm{CNC}$ weight ratio of 0.7 in $0.1 \mathrm{M}$ acetate buffer of $\mathrm{pH} 4$ and $50 \mathrm{mM}$ ionic strength and results in dialdehyde cellulose (Fig. 1c). The concentration of CNCs was $3 \mathrm{wt} \%$. The DO was controlled by reaction time. Glycerol was used to quench the reaction. After oxidation, the suspensions were dialyzed in order to remove the residual periodate, iodate and glycerol. The suspensions were then stored at $4{ }^{\circ} \mathrm{C}$. As the sodium metaperiodate molecule is larger than the space between the cellulose crystals, the oxidation reaction is expected to take place on the crystal surface. The reaction has been reported to be heterogeneous (Liu et al. 2012). With the aim of decreasing the level of analysis complexity, a number of assumptions were made in order to fit the reaction to pseudo first-order kinetics (Eq. 1). These were: $i$ ) The reaction is slow and is not limited by the mass transfer with no brush formation on the surface causing diffusion limitations to further reaction; ii) The reaction is stoichiometric 1 to 1 and no side-reactions take place; iii) The CNC concentration has low impact on the rate. Thus, there is a linear dependence on the concentration of the periodate and the rate:

$\frac{[P]}{\left[P_{0}\right]}=e^{-k^{\prime} \cdot t}$

The pseudo first-order kinetics on the periodate is shown in Equation 1 where $\left[P_{0}\right]$ is the initial molar concentration of periodate, $[P]$ the periodate molar concentration, $k^{\prime}$ the reaction rate, and $t$ the time.

Methods

Elemental analysis was performed by Mikrolab Kolbe in Germany. The X-ray photoelectron spectroscopy (XPS) analysis was performed using a PHI 5000 VersaProbe III Scanning XPS Microprobe at an angle of $45^{\circ}$. Fourier-transform infrared spectroscopy (FTIR) was recorded using a spectrometer (PerkinElmer) and potassium bromide $(\mathrm{KBr})$ tablets were used to carry the specimen. $\mathrm{KBr}$ and the analytes were kept at $50{ }^{\circ} \mathrm{C}$ for $5 \mathrm{~h}$ to remove water prior to grinding and tableting. The specimens were stored in a desiccator prior to analysis. Wide-angle X-ray scattering (WAXS) was performed using SAXSLab (Mat:Nordic).

Solid-state NMR spectroscopy was performed using a Bruker $400 \mathrm{MHz}$ instrument operating at 100.6 MHz for ${ }^{13} \mathrm{C}$ with a $3.2 \mathrm{~mm}$ solid-state magicangle-spinning (MAS) probe head. Measurements were conducted at $298 \mathrm{~K}$ with a MAS spinning rate of $12 \mathrm{kHz}$. One-dimensional ${ }^{13} \mathrm{C}$ Cross-Polarization Magic-Angle Spinning (CP/MAS) spectra were acquired with a $3.0 \mu \mathrm{s}{ }^{1} \mathrm{H} 90^{\circ}$ pulse, $2000 \mu \mathrm{s} \mathrm{CP}$ contact time, $33 \mathrm{~ms}$ acquisition time with proton decoupling, and $2 \mathrm{~s}$ recycle delay. The number of acquisitions for the CP/MAS spectra was 2048 times with ${ }^{13} \mathrm{C}$ in natural abundance. Chemical shift were 
calibrated indirectly through $\alpha$-glycine carbonyl peak $(\mathrm{C}=\mathrm{O})$ observed at $176 \mathrm{ppm}$ relative to tetramethyl silane (TMS) at $0 \mathrm{ppm}$.

The zeta potential of the dispersions was determined using the Zetasizer Nano (Malvern). The measurements were performed at $25.0 \pm 0.1{ }^{\circ} \mathrm{C}$ and in $0.1 \mathrm{M}$ acetate buffer at $\mathrm{pH} 4$ with $0.25 \mathrm{wt} \%$ suspensions. The data was processed by Malvern Zetasizer Software v7.13. The zeta potential was calculated as the average of 6 measurements, where each measurement was comprised of 30 to 150 subruns.

Semi-contact mode atomic force microscopy (AFM, NTEGRA, NT-MDT, Russia) with Tap300AI-G tips were used for morphology characterization of the CNCs deposited on the silicon wafers (Siegert wafers, Germany). Regions of interest of $5 \times$ $5 \mu \mathrm{m}$ were recorded for calculating the dimensions of the CNCs. Significant amounts of potentially single CNC profiles were extracted using the software Gwyddion 2.56 after removing polynomial backgrounds and aligning the rows of the $5 \times 5 \mu \mathrm{m}$ images. The profiles were baseline corrected using polynomial fitting; the height was calculated from the resulting profile.

Determination of the sulfate half-ester content

Sulfate half-ester content was determined using elemental analysis, XPS and FTIR analyses. The determination of the amount of half-ester groups from the elemental analysis and XPS was performed by fitting the contributions of substituted and unsubstituted AGUs to the experimental data obtained. The monosaccharide compositions considered were AGUs, AGUs with a sulfate half-ester assumed to reside at carbon 6 and 2,3-dialdehyde-AGUs (Fig. 1). The fitting searched the minimum molar percentage error for all components analyzed, excluding $\mathrm{Na}^{+}$. For analysis based on XPS data, oxygen, sulfur and carbon were considered.

FTIR data was normalized to $1060 \mathrm{~cm}^{-1}$ and the baseline was corrected. The area used for the sulfate was from $770-868 \mathrm{~cm}^{-1}$ ( $\mathrm{Gu}$ et al. 2010). The calculated areas were divided by the $\mathrm{CNC}$ areas and multiplied by the amount of sulfur (S) detected in the elemental analysis of the initial material.
Determination of the degree of oxidation

The DO during the oxidation reaction was tracked using the periodate consumption by observing UV absorbance at $290 \mathrm{~nm}$ (Malaprade 1928). The reaction of hydroxylamine hydrochloride with the carbonyl groups (Zhao and Heindel 1991) was used to determine the DO of the products. The DO was determined using an aliquot, containing $0.1 \mathrm{~g}$ dry mass of the oxidized CNC derivative and $0.25 \mathrm{M}$ hydroxylamine hydrochloride tuned to $\mathrm{pH} 4$ and stirred for 2.5 hours at room temperature (approx. $20{ }^{\circ} \mathrm{C}$ ) to ensure to complete the reaction. The solution was titrated back to $\mathrm{pH} 4$ with $0.01 \mathrm{M} \mathrm{NaOH}$ using SI Analytics TitroLine 7000. The method is referred to as titration. Elemental analysis was also used for establishing the DO by fitting the contributions of substituted and unsubstituted AGUs to the experimental data obtained.

A method based on solid-state ${ }^{13} \mathrm{C}$ CP/MAS NMR was also used (Leguy et al. 2018) in the determination of DO. As a first approximation, it was assumed that the signals of the remaining unmodified cellulose after periodate treatment were the same as in the starting material. Since the $\mathrm{C} 1$ signal of cellulose at $104 \mathrm{ppm}$ is the only region where the spectra of untreated cellulose and fully oxidized cellulose do not overlap, it was used to calculate the DO using the $\mathrm{C} 1$ integral of oxidized cellulose $\left(\int \mathrm{C} 1\right)$ relative to the one of the corresponding non-oxidized cellulose $\left(\int \mathrm{C}_{0}\right)$. After normalizing the entire spectrum to unity, the $\mathrm{C} 1$ integral was calculated from deconvolution. The degree of oxidation determined by NMR spectroscopy $\left(\mathrm{DO}_{\mathrm{NMR}}\right)$ is defined by the number of aldehyde groups per glycosyl residue and calculated using in Eq. 2.

$$
\mathrm{DO}_{\mathrm{NMR}}=\left(1-\frac{\int \mathrm{C} 1}{\int \mathrm{C} 1_{0}}\right)
$$

Determination of the crystallinity index

WAXS analysis was used to determine the crystallinity index $\left(\mathrm{CI}_{\mathrm{WAXS}}\right)$ and the crystallite size of selected CNCs. The diffraction patterns obtained were deconvoluted to Voigt functions using OriginPro (2021). The crystallinity (Eq. 3) was calculated using the crystalline area, $A_{\text {crystal }}$, and the amorphous area, $A_{\text {amorphous }}$, which peak was located approximately at an 
angle $2 \theta$ of $18^{\circ}$. The crystalline area was composed by the crystalline areas of the following peaks: (101), $(10 \overline{1}),(021),(002)$ (Eq. 4). The crystallite size was determined using the Scherrer equation, using 0.9 as the correction factor (Nam et al. 2016).

$$
\begin{aligned}
& \mathrm{CI}_{\mathrm{WAXS}}(\%)=\left(\frac{A_{\text {crystal }}}{A_{\text {amorphous }}+A_{\text {crystal }}}\right) \cdot 100 \\
& A_{\text {crystal }}=A_{101}+A_{10 \overline{1}}+A_{012}+A_{002}
\end{aligned}
$$

The CI was also calculated by FTIR, $\mathrm{CI}_{\mathrm{FTIR}}$, using the method by Siller et al. (2015). The CIFTIR was calculated from the ratio of the peak heights at 1370 over 2900 (Nelson and O'Connor 1964).

In addition to WAXS and FTIR, crystallinity index was also determined by solid-state NMR spectroscopy. Using a deconvolution-based method presented elsewhere (Palme et al. 2014), the informative $\mathrm{C} 4$ region was used to obtain $\mathrm{CI}$.

Determination of the degree of surface substitution

The surface ratio $\left(R_{\text {sur }}\right)$ was defined as the ratio between the number of surface cellulose chains, $n_{\text {sur }}$, and the total number of cellulose chains of the CNCs. The $R_{\text {sur }}$ was calculated using WAXS data and Eq. 5, where $d_{(110)}$ and $d_{(1 \overline{1} 0)}$ are the plane spacings, $L_{2}$ and $L_{1}$ are the height and the width of the crystal, respectively (Habibi et al. 2006; Eyley and Thielemans 2014).

$$
R_{\text {sur }}=\frac{n_{\text {sur }}}{\sum n}=\frac{2\left(\frac{L_{1}}{d_{(110)}}\right)+2\left(\frac{L_{2}}{d_{(110)}}\right)}{\frac{L_{1} L_{2}}{d_{(110)} d_{(110)}}}
$$

The degree of surface substitution (DSS) of DO, $\mathrm{DSS}_{\mathrm{DO}}$ (Eq. 6), and the sulfate half-ester groups, $\mathrm{DSS}_{\mathrm{S}}$ (Eq. 7), were determined as being the amount of 2,3dialdehyde-AGUs, $n_{\mathrm{ox}}$, and AGUs with the sulfate half-ester, $n_{\mathrm{S}}$, per surface cellulose chains. The degree of surface sites used, $\mathrm{DSS}_{U}$, was defined as the percentage of the surface modified AGUs and the actual surface of the AGUs that was modifiable (Eq. 8). Due to the $180^{\circ}$ angle of the $\beta$-1,4-glycosidic linked glucose units, every other superficial AGU was considered modifiable by oxidation. Thus, the $\mathrm{DSS}_{U}$ was calculated as the number of molecules substituted by the surface molecules modifiable by periodate oxidation. In Eq. 7, $\mathrm{c}_{\mathrm{S}}$ is the sulfur molar concentration from elemental analysis.

$$
\begin{aligned}
& \mathrm{DSS}_{\mathrm{DO}}=\frac{n_{\mathrm{ox}}}{n_{\mathrm{sur}}}=\frac{\mathrm{DO}}{R_{\mathrm{sur}}} \\
& \mathrm{DSS}_{\mathrm{S}}=\frac{n_{\mathrm{S}}}{n_{\mathrm{sur}}}=\frac{c_{\mathrm{S}}}{R_{\mathrm{sur}}} \\
& \mathrm{DSS}_{\mathrm{U}}=\frac{n_{\mathrm{ox}}}{\frac{n_{\text {sur }}}{2}}
\end{aligned}
$$

\section{Statistical analysis}

The statistical analysis performed in this paper, namely linear fittings, non-linear fittings, descriptive statistics, F-test and ANOVA with the BonferroniHolm test, were performed using the software OriginLab Pro (2021). The variations are considered significant at $P$-values less than 0.05 .

\section{Results and discussion}

Oxidation kinetics and composition of the CNCs

According to the elemental analysis (Table 1), a sulfate half-ester group resided in every 18th glucose unit present prior to desulfation, and was reduced to every 69th unit after desulfation. The CNC and the desulfCNCs were subjected to periodate oxidation. The consumption of sodium periodate was monitored

Table 1 Elemental analysis of sulfur in the CNCs expressed as $\mathrm{wt} \%$. The DO, degree of oxidation is based on periodate consumption determination by UV absorbance. The standard deviation was less than $0.02 \mathrm{wt} \%$

\begin{tabular}{lll}
\hline Specimen & DO $(\%)$ & S (wt $)$ \\
\hline CNC & - & 1.09 \\
DAC & 12 & 0.71 \\
DAC & 29 & 0.69 \\
DAC & 57 & 0.66 \\
desulfCNC & - & 0.29 \\
desulfDAC & 13 & 0.30 \\
desulfDAC & 33 & 0.26 \\
desulfDAC & 53 & 0.24 \\
\hline
\end{tabular}


in situ by determining the UV absorbance (Fig. 2), which was fitted to a pseudo first-order kinetic reaction (Liu et al. 2012). The calculated reaction rate of the consumption periodate for the oxidation of $\mathrm{CNC}$ was $k_{1}^{\prime}=-1.98^{-5} \pm 1 \cdot 10^{-6} \mathrm{~s}^{-1}$. The reaction rate for the desulfCNCs was higher with $k_{2}^{\prime}=-5.09 \cdot 10^{-5} \pm 4 \cdot 10^{-6}$ $\mathrm{s}^{-1}$. Both regressions were considered acceptable according to the R-square. The assumption of a linear dependence on the periodate concentration $[\mathrm{P}]$ and the negligible impact of the $\mathrm{CNC}$ concentration [AGU] on the rate $(r)$ suggested that $r=k[\mathrm{AGU}]^{x}[\mathrm{P}]^{y}$, for which $x$ and $y$ are the orders (power dependence of rate on the concentration of the reactant) for each reactant, the order for the AGU was $x<<1$. There is a linear dependence of the rate on the periodate concentration (Fig. 2). The reaction rates were statistically different according to the F-test. The decrease in the content of sulfate half-ester groups on the surface increased the reaction rate coefficient by approx. $150 \%$. The oxidized CNCs and desulfCNCs are referred to as DAC and desulfDAC, respectively.

Periodate oxidation of cellulose with sulfate halfester groups should result in no change in the sulfur content if the sulfate half-ester groups reside in the C6 position, since that position will be unaffected by regioselective oxidation. The decreasing content of $\mathrm{S}$ (Table 1) implies that the sulfate groups are affected

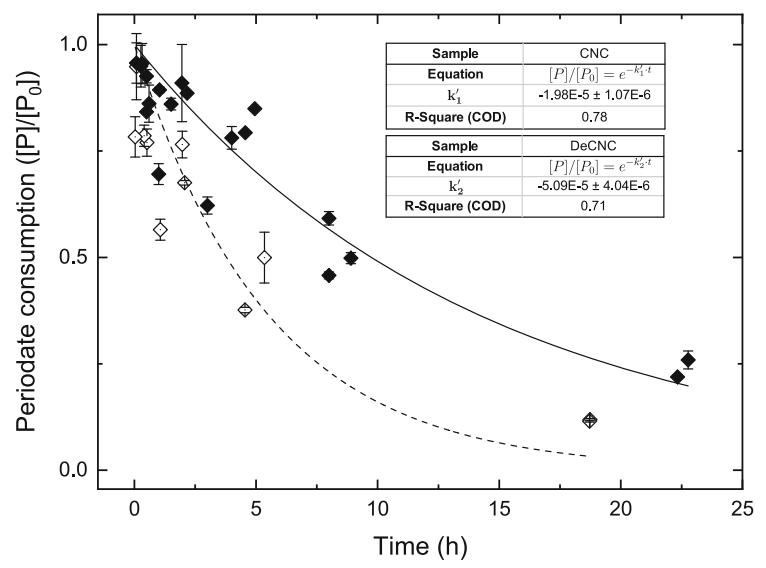

Fig. 2 Consumption of periodate during the oxidation of the CNCs (Filled diamond) and desulfCNCs (open diamond). The equations containing $k_{1}^{\prime}$ and $k_{2}^{\prime}$ correspond to $\mathrm{CNC}$ and desulfCNC, respectively. R-square, i.e., the coefficient of determination (COD), qualifies the regression. These curves are comprised of three oxidation series for each CNC derivative. Selected points are excluded for clarity but are included in the fitting and statistical analysis and removed during the oxidation. Where the oxidation of desulfCNC is concerned, the amount decreased slightly and the difference from the first point to the second point was within the standard deviation of the analysis. The $\mathrm{O} / \mathrm{S}$ ratio (Table $\mathrm{S} 2$, Supplementary Information) increased for both CNC and desulfCNC when oxidized. In the case where sulfate half-ester groups are not affected, this ratio should not increase with the increasing degree of oxidation. However, the amount of sulfate half-ester groups in the material decreases as the DO of the CNCs increased, regardless of the analysis method used: elemental analysis, FTIR spectroscopy or XPS (Fig. 3).

We compared the DO determined by analysis of reactant consumption to the DO values that were determined using titration, solid-state NMR spectroscopy and elemental analysis of the oxidized CNC derivatives (Fig. 4). NMR spectroscopy was only performed for the highest DOs used in this study ( $\sim 50 \%$ ). In Fig. 5, the ${ }^{13} \mathrm{C} \mathrm{CP/MAS} \mathrm{NMR} \mathrm{spectra} \mathrm{of}$ CNC, desulfCNC, DAC and desulfDAC are shown. The absence of signals in the 160-200 ppm region for DAC and desulfDAC indicate that there are no aldehyde groups in these materials. This absence can be explained by the fact that the aldehydes have reformed with neighboring hydroxyl groups to provide various hemiacetal and/or hemialdal entities, previously shown to appear as broad peaks in the 90-100 ppm region (Guigo et al. 2014; Azzam et al. 2015;

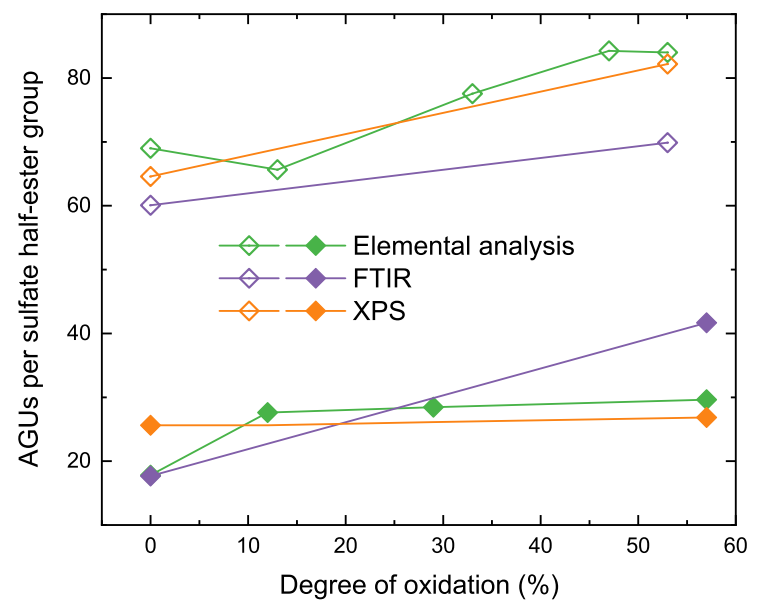

Fig. 3 AGUs per sulfate half-ester groups in CNC and DAC (Filled diamond) and desulfCNC and desulfDAC (open diamond) with respect to the DO calculated using elemental analysis (green), FTIR area $770-868 \mathrm{~cm}^{-1}$ (purple) and XPS analysis (orange) 

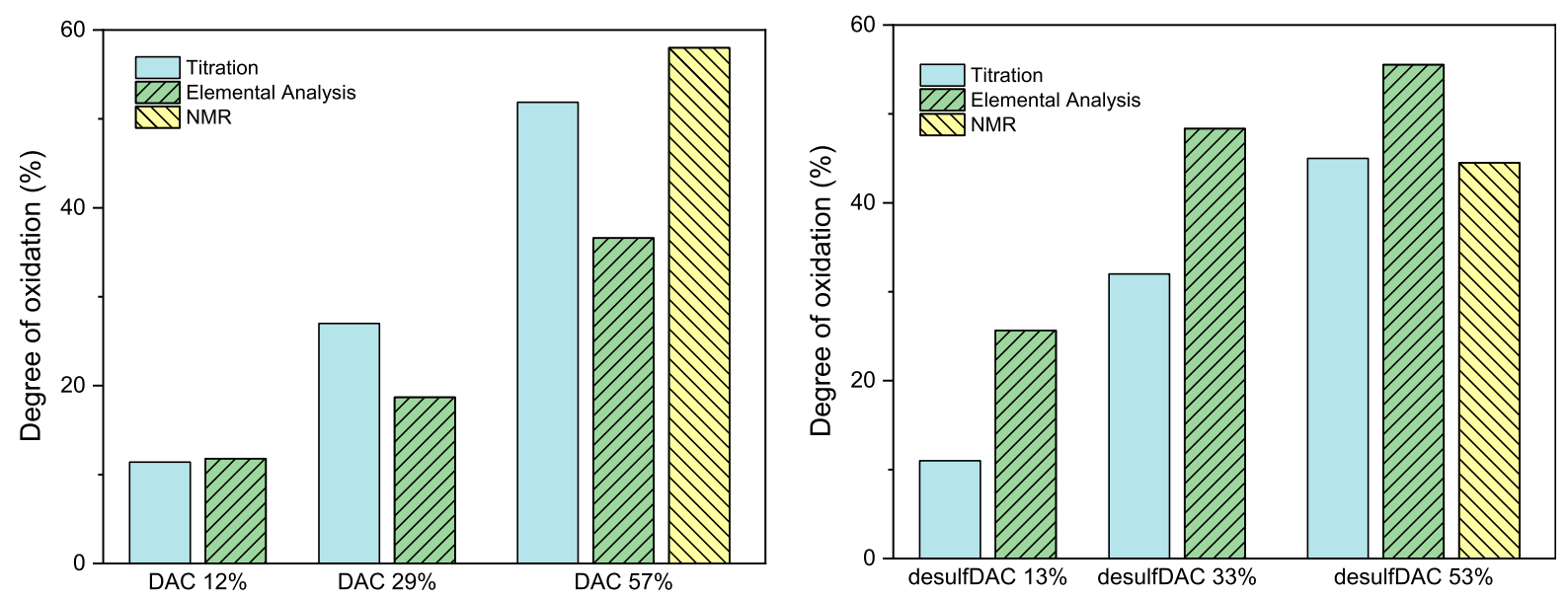

Fig. 4 Degree of oxidation, DO, according to titration (cyan), elemental (green) and NMR spectroscopy (yellow) analysis for DACs and desulfDACs. DO on X-axis is based on periodate consumption determination by UV absorbance

Fig. $5{ }^{13} \mathrm{C}$ CP/MAS NMR spectra of a CNC,

b desulfCNC, $\mathbf{c}$ DAC, and d desulfDAC. Deconvoluted signals in the spectrum are attributed to the different cellulose moieties of the cellulose fibril model, with crystalline and

paracrystalline (cry) signals in blue, non-crystalline (non-cry) accessible fibril surface and inaccessible fibril signals in green, and overlapping cellulose oligomer signals in red. Several broad signals were added, shown in gray, to correct for the oxidized material. The sum of the deconvolution is shown by dotted gray line

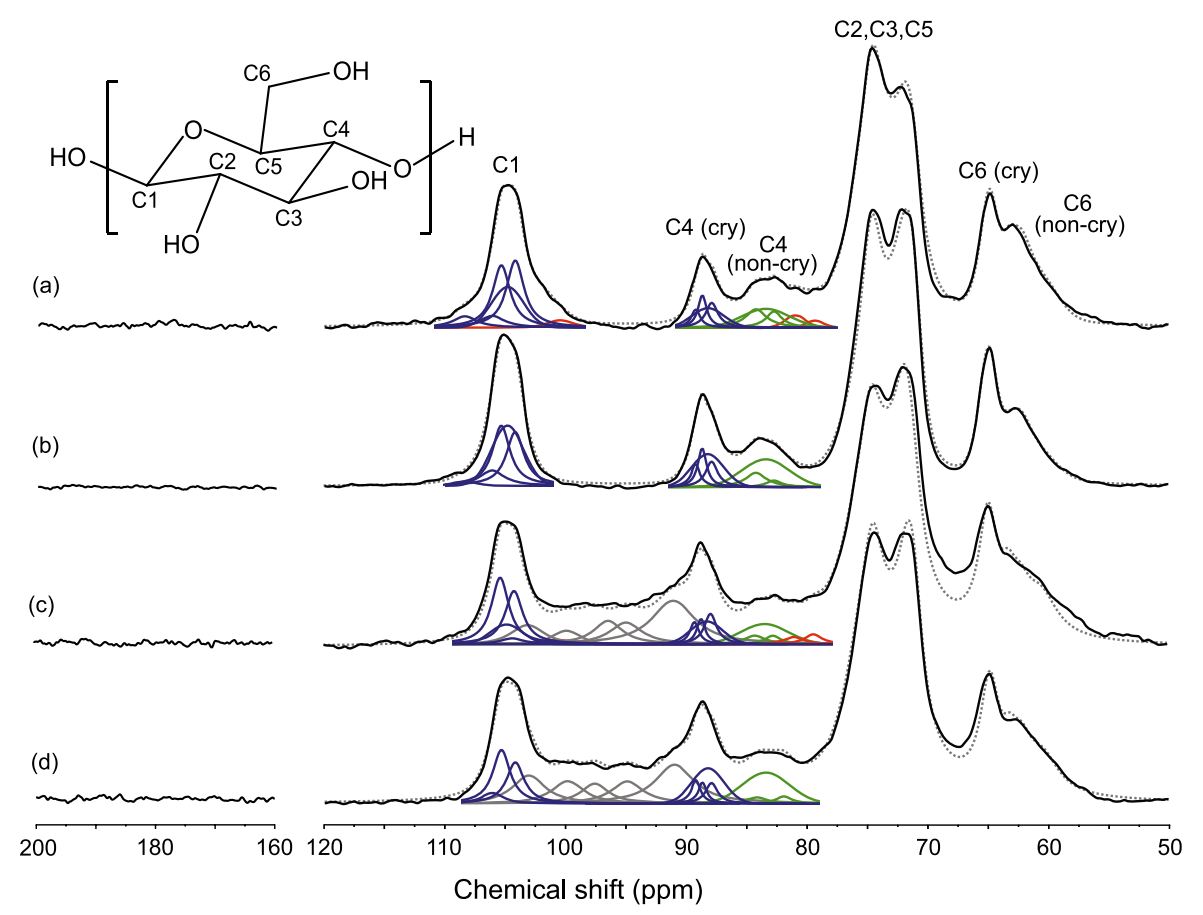

Codou et al. 2015). These newly formed signals overlap with the $\mathrm{C} 1$ and $\mathrm{C} 4$ signals, and in order to correct for this in the DO calculation, deconvolution of the affected area was performed (see Supplementary Information Table S1 for all parameters). For the CNC and desulfCNC, the number of deconvolution signals were selected according to the native cellulose fibril model, and signals were decomposed into Lorentzian and Gaussian functions for crystalline and amorphous contributions, respectively (Heux et al. 1999; Hult et al. 2002). For the DAC and desulfDAC, in addition to the signals above, several Gaussian signals were added to correct for the oxidized material. The deconvolution of this new broad peak area was performed using literature describing oxidized cellulose structures (Plappert et al. 2018; Nypelö et al. 2021), however to fully assign these signals remains a future work. As the $\mathrm{C} 1$ signal is consumed during 
oxidation, the DO could be determined using the Eq. 2, and the results obtained were in good agreement with both the titration and the UV absorbance measurements. The DO calculated for the oxidized CNC by elemental analysis was lower compared to the other methods, while the DO calculated by elemental analysis for the desulfCNC was higher than for the other methods employed. This discrepancy could be due to the low accuracy of the method in finding the difference between AGU and dialdehyde-AGU within the elements used for the analysis and the reducing end of cellulose was not taken into account.

The sulfate half-esters provide electrostatic repulsion, and hence, colloidal stability. The zeta potential of the CNCs was $-28 \mathrm{mV}$ and desulfation increased it to $-19 \mathrm{mV}$ (Fig. 6). An increase in the DO led to an increase in the zeta potential of both grades. When the DO was approx. $50 \%$, the zeta potential of both grades was approx. $-5 \mathrm{mV}$ and the low zeta potential manifested the colloidal instability.

\section{CNC dimensions}

The decrease in the sulfur content of DACs implies that the sulfate half-ester groups were affected by oxidation. We suggest that this decrease in $\mathrm{S}$ content was caused either by the cleaving off of the sulfate half-ester groups or by the peeling off of cellulose chains from the surface, which are then removed during purification via dialysis. The diameter of the CNCs and desulfCNCs, $4.1 \pm 1.0$ and $4.0 \pm 1.5 \mathrm{~nm}$,

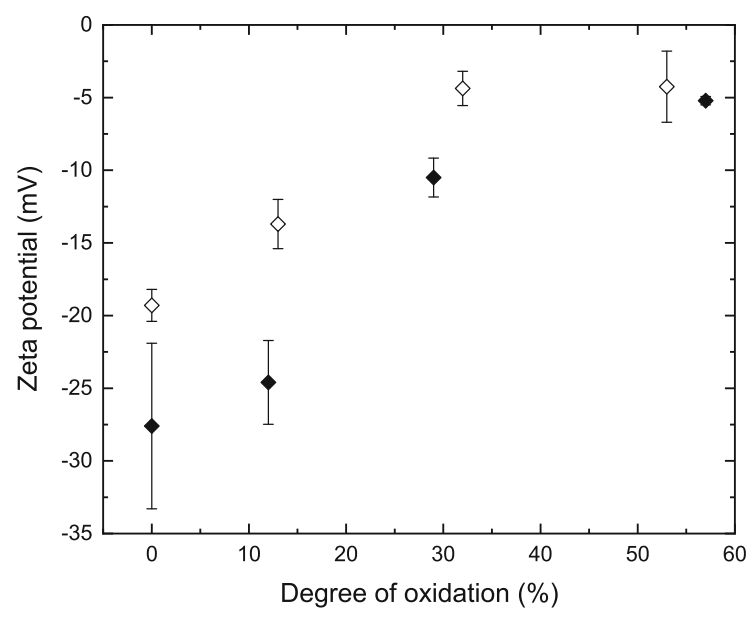

Fig. 6 Zeta potential of CNC and DAC (Filled diamond) and desulfCNC and desulfDAC (open diamond) suspensions respectively (Fig. 7), were statistically not different (Table S3, Supplementary information) thereby suggesting that desulfation did not decrease the diameter of the CNC. Oxidation of CNCs into DAC with a DO of $57 \%$ led to a decrease in the diameter down to $3.0 \pm$ $0.8 \mathrm{~nm}$. The average diameters of the CNC and DAC were statistically different, supporting the hypothesis that cellulose chains peel off due to oxidation. The average diameter of desulfDAC, however, increased. The desulfDAC with a DO of $53 \%$ was not statistically different from the non-oxidized grades, hence not supporting the hypothesis of oxidation leading to peeling off of CNC surface chains. We did, however, note that the desulfDAC aggregated in the suspension, as evidenced by the close to neutral zeta potential (Fig. 6), and consequently on the silicon support, thereby increasing uncertainty in the determination of diameter.

Crystallinity

Desulfation, which uses an acid that cleaves the sulfate half-ester groups, resulted in CI increasing in all three methods studied (Fig. 8). Besides, cleaving off the sulfate half-ester groups, the acid appeared to remove regions of less organized polysaccharide. This is, indeed, directly seen in Fig. 5a by the overall NMR spectral sharpening of the desulfCNC compared to CNC, particularly in the $\mathrm{C} 1(100-113 \mathrm{ppm})$ and $\mathrm{C} 4$ (79-92 ppm) regions. Periodate oxidation has been shown to decrease the CI of cellulose (Liu et al. 2012)

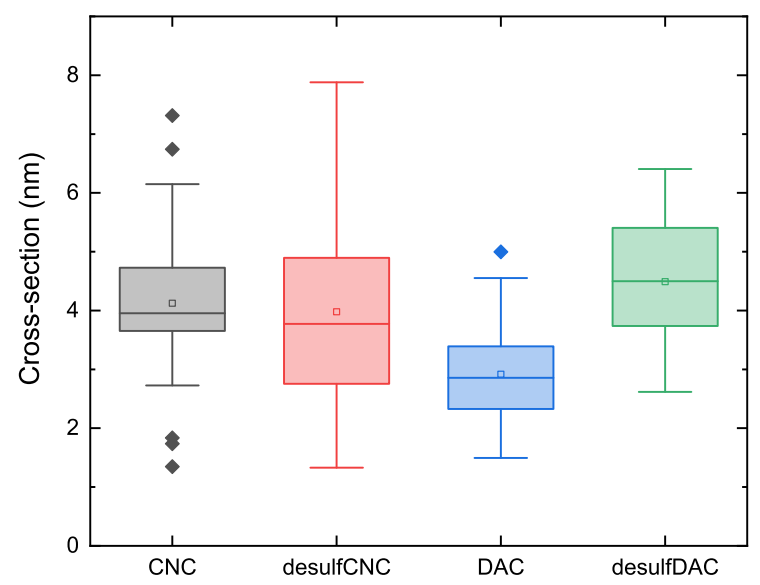

Fig. 7 Dimensions of the CNCs determined using AFM analysis of height profiles. The degree of oxidation of DAC and desulfDAC was $57 \%$ and $53 \%$, respectively 


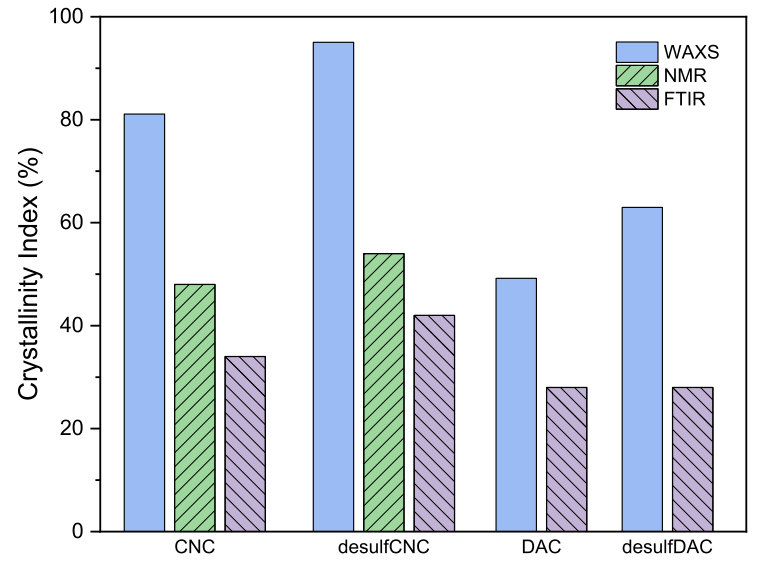

Fig. 8 Crystallinity index, CI, of CNC, desulfCNC and their oxidized derivates DAC and desulfDAC in DO 57\% and 53\%, respectively. The $\mathrm{CI}$ was determined using wide angle $\mathrm{X}$-ray analysis (blue), NMR spectroscopy (green, only for CNC and desulfCNC) and FTIR (purple)

and consequently, the $\mathrm{CI}$ of oxidized grades decreased compared to the non-oxidized $\mathrm{CNC}$ and desulfCNC using WAXS and FTIR (Fig. 8). For the DAC and desulfDAC the spectral resolution was too poor to determine the CI using NMR. In general, the $\mathrm{CI}_{\text {WAXS }}$ was higher than the CI calculated by NMR spectroscopy and FTIR due the inherent methods (Park et al. 2010).

\section{Degree of surface substitution}

The ratio between the cellulose chains present on the surface and the total cellulose chains, $R_{\text {sur }}$ (Table 2), increased with oxidation, which implies a reduction in diameter. The unit cell is considered as remaining unaltered so the smaller the diameter, the larger the fraction of cellulose chains located on the surface. The degree of surface functionality of the $\mathrm{CNC}$ derivatives

Table 2 Distribution of the moieties on the surface of the CNC derivates. S: Number of molecules per each sulfate half-ester group. DO: degree of oxidation from UV absorbance. $R_{\text {sur }}$ : ratio of molecules on the surface per total molecules. DSS degree of surface substitution of $S$ on all the molecules on the is shown in Table 2. The $\mathrm{DSS}_{\mathrm{S}}$ decreased, as expected, with desulfation but also with oxidation due to the $\mathrm{S}$ content decreasing (Table 1 and Fig. 4), thereby complying with the findings of Lin and Dufresne (2014). At the degree of oxidation $57 \%$ and $53 \%$ for DAC and desulfDAC, respectively, in the oxidized grades, the $\mathrm{DSS}_{\mathrm{DO}}$ indicated that almost all of the chains present on the surface were oxidized.

The rotation of AGUs due to the glycosidic bond means, however, that not all of the functionalities can be placed on the surface of every cellulose molecule: the substitution present on both oxidized grades, i.e., DAC and desulfDAC, therefore almost doubled the number of sites accessible on the surface for such a degree of modification. The requirement that such a high degree of surface be available suggests that those functionalities were located elsewhere than on the surface, which we suggest were in chains that had been peeled off during oxidation.

\section{Conclusions}

Sulfate half-ester groups are present in most industrially available CNCs. Oxidation using periodate is a way of oxidizing the cellulose by opening the ring structure, equipping the molecule with aldehyde or alcohol functionality and altering, for example, reactivity and the thermal deformability. However, the role played by sulfate half-ester groups in periodate oxidative modification and its products has not previously been elucidated. The understanding of their impact and function is crucial for further chemical modifications.

We have demonstrated that the sulfate half-ester groups decrease the oxidation reaction rate. Increasing

surface. $\mathrm{DSS}_{\mathrm{DO}}$ : degree of surface substitution of dialdehydes on all the molecules on the surface. $\mathrm{DSS}_{\mathrm{U}}$ : degree of surface sites used by periodate oxidation to achieve such amounts of moieties on the surface

\begin{tabular}{lllllll}
\hline Sample & $\mathrm{S}$ & $\mathrm{DO}(\%)$ & $R_{\text {sur }}(\%)$ & $\mathrm{DSS}_{\mathrm{S}}(\%)$ & DSS $_{\text {DO }}(\%)$ & DSS $_{\mathrm{U}}(\%)$ \\
\hline CNC & 18 & 0 & 38 & 15.0 & 0 & 0 \\
desulfCNC & 69 & 0 & 38 & 3.8 & 0 & 0 \\
DAC & 30 & 57 & 56 & 6.0 & 102 & 203 \\
desulfDAC & 84 & 53 & 53 & 2.2 & 100 & 200 \\
\hline
\end{tabular}


the degree of oxidation led to a decrease in the sulfate half-ester group content independent of its initial content, which was proven not only by a decrease in sulfur content, but also by an increase in the zeta potential. The control of the desulfation by oxidation could lead to a DAC with the desired colloidal properties. The conclusion we draw is that desulfation is due to the peeling-off of the cellulose chains from the CNC surfaces.

A scenario in which an aldehyde functionality was introduced to the use of CNCs has been examined. In this particular situation, it is necessary that the effect had by the sulfate half-ester groups on the reaction time and conditions is known in order to optimize the reaction. Moreover, improving knowledge of how the sulfate half-ester group content develops (i.e., decreases) with oxidation allows us to contribute to creating materials in which they are desired in varying amounts together with the aldehyde functionality. Lastly, we have made discoveries pertaining to the degradation mechanism of the crystalline cellulose during periodate oxidation via observations of the sulfur content, which we then employed as a direct measurement of the loss of the surface layers on CNCs.

\section{Supplementary information}

NMR spectroscopy deconvolution chemical shifts and line widths. Complete elemental analysis. BonferroniHolm test comparing the dimensions of the CNC derivatives.

Acknowledgments Anne Wendel and Adrián Rodriguez, at Chalmers University of Technology, are acknowledged for the XPS and WAXS measurements, respectively, and Chalmers Materials Analysis Laboratory (CMAL) for allowing WAXS and XPS to be used. Johan Bergenholtz, at the University of Gothenburg, is thanked for enabling the zeta potential measurements to be made. The NMR measurements were carried out at the Swedish NMR Centre, Gothenburg, Sweden.

Funding Open access funding provided by Chalmers University of Technology. We are grateful for the financial support of Wallenberg Wood Science Center and the Materials Science Area of Advance at Chalmers.

\section{Declarations}

Conflict of interest The authors declare that they have no conflict of interest.
Open Access This article is licensed under a Creative Commons Attribution 4.0 International License, which permits use, sharing, adaptation, distribution and reproduction in any medium or format, as long as you give appropriate credit to the original author(s) and the source, provide a link to the Creative Commons licence, and indicate if changes were made. The images or other third party material in this article are included in the article's Creative Commons licence, unless indicated otherwise in a credit line to the material. If material is not included in the article's Creative Commons licence and your intended use is not permitted by statutory regulation or exceeds the permitted use, you will need to obtain permission directly from the copyright holder. To view a copy of this licence, visit http://creativecommons.org/licenses/by/4.0/.

\section{References}

Azzam F, Galliot M, Putaux JL, Heux L, Jean B (2015) Surface peeling of cellulose nanocrystals resulting from periodate oxidation and reductive amination with water-soluble polymers. Cellulose 22(6):3701-3714. https://doi.org/10. 1007/s10570-015-0785-x

Codou A, Guigo N, Heux L, Sbirrazzuoli N (2015) Partial periodate oxidation and thermal cross-linking for the processing ofthermosetall-cellulose composites. Compos Sci Technol 117:54-61. https://doi.org/10.1016/j. compscitech.2015.05.022

Conley K, Whitehead MA, van de Ven TG (2017) Probing the structural chirality of crystalline cellulose with induced circular dichroism. Cellulose 24(2):479-486. https://doi. org/10.1007/s10570-016-1130-8

Dash R, Foston M, Ragauskas AJ (2013) Improving the mechanical and thermal properties of gelatin hydrogels cross-linked by cellulose nanowhiskers. Carbohydr Polym 91(2):638-645. https://doi.org/10.1016/j.carbpol.2012.08. 080

Eyley S, Thielemans W (2014) Surface modification of cellulose nanocrystals. Nanoscale 6(14):7764-7779. https://doi.org/ 10.1039/C4NR01756K

Gu J, Catchmark JM, Archibald DD, Kaiser EQ (2010) Determination of sulfate esterification levels in cellulose nanocrystals by attenuated total reflectance - Fourier transform infrared spectroscopy. American Society of Agricultural and Biological Engineers Annual International Meeting 2010, ASABE 2010 1(10):23-32. https:// doi.org/10.13031/2013.29598

Guigo N, Mazeau K, Putaux JL, Heux L (2014) Surface modification of cellulose microfibrils by periodate oxidation and subsequent reductive amination with benzylamine: a topochemical study. Cellulose 21(6):4119-4133. https:// doi.org/10.1007/s10570-014-0459-0

Habibi Y, Chanzy H, Vignon MR (2006) TEMPO-mediated surface oxidation of cellulose whiskers. Cellulose 13(6):679-687. https://doi.org/10.1007/s10570-006-9075-y

Heux L, Dinand E, Vignon M (1999) Structural aspects in ultrathin cellulose microfibrils followed by $13 \mathrm{C} \mathrm{CP-MAS}$ 
NMR. Carbohydr Polym 40(2):115-124. https://doi.org/ 10.1016/S0144-8617(99)00051-X

Hult EL, Larsson PT, Iversen T (2002) A comparative CP/MAS 13C-NMR study of the supermolecular structure of Polysaccharides in sulphite and kraft pulps. Holzforschung 56(2):179-184. https://doi.org/10.1515/HF.2002.030

Jiang F, Esker AR, Roman M (2010) Acid-catalyzed and solvolytic desulfation of $\mathrm{H}_{2} \mathrm{SO}_{4}$-hydrolyzed cellulose nanocrystals. Langmuir 26(23):17, 919-17, 925. https:// doi.org/10.1021/la1028405

Jordan JH, Easson MW, Condon BD (2019) Alkali hydrolysis of sulfated cellulose nanocrystals: optimization of reaction conditions and tailored surface charge. Nanomaterials 9(9):1232. https://doi.org/10.3390/nano9091232

Kim UJ, Kuga S, Wada M, Okano T, Kondo T (2000) Periodate oxidation of crystalline cellulose. Biomacromolecules 1(3):488-492. https://doi.org/10.1021/bm0000337

Kontturi E, Laaksonen P, Linder MB, Nonappa Gröschel AH, Rojas OJ, Ikkala O (2018) Advanced materials through assemblyof nanocelluloses. Adv Mater 30:1703779. https://doi.org/10.1002/adma.201703779

Koso T, Rico del Cerro D, Heikkinen S, Nypelö T, Buffiere J, Perea-Buceta JE, Potthast A, Rosenau T, Heikkinen H, Maaheimo H, Isogai A, Kilpeläinen I, King AWT (2020) 2D Assignment and quantitative analysis of cellulose and oxidized celluloses using solution-state NMR spectroscopy. Cellulose 27(14):7929-7953. https://doi.org/10. 1007/s10570-020-03317-0

Larsson PA, Berglund LA, Wågberg L (2014) Highly ductile fibres and sheets by core-shell structuring of the cellulose nanofibrils. Cellulose 21(1):323-333. https://doi.org/10. 1007/s10570-013-0099-9

Leguy J, Nishiyama Y, Jean B, Heux L (2018) Ultrastructural characterization of the core-shell structure of a wide range of periodate-oxidized cellulose from different native sources by solid-state ${ }^{13} \mathrm{C}$ CP-MAS NMR. ACS Sustain Chem Eng 7(1):412-420. https://doi.org/10.1021/ acssuschemeng.8b03772

Liimatainen H, Visanko M, Sirviö JA, Hormi OE, Niinimäki J (2012) Enhancement of the nanofibrillation of wood cellulose through sequential periodate-chlorite oxidation. Biomacromolecules 13(5):1592-1597. https://doi.org/10. 1021/bm300319m

Lin N, Dufresne A (2014) Surface chemistry, morphological analysis and properties of cellulose nanocrystals with gradiented sulfation degrees. Nanoscale 6(10):5384-5393. https://doi.org/10.1039/C3NR06761K

Liu X, Wang L, Song X, Song H, Zhao JR, Wang S (2012) A kinetic model for oxidative degradation of bagasse pulp fiber by sodium periodate. Carbohydr Polym 90:218-223. https://doi.org/10.1016/j.carbpol.2012.05.027

López Durán V, Larsson PA, Wågberg L (2018) Chemical modification of cellulose-rich fibres to clarify the influence of the chemical structure on the physical and mechanical properties of cellulose fibres and thereof made sheets. Carbohydr Polym 182:1-7. https://doi.org/10.1016/j. carbpol.2017.11.006

Malaprade L (1928) Oxidation of some polyalcohols by periodic acid-applications. Comptes Rendus 186:382-384

Nam S, French AD, Condon BD, Concha M (2016) Segal crystallinity index revisited by the simulation of X-ray diffraction patterns of cotton cellulose I $\beta$ and cellulose II. Carbohydr Polym 135:1-9. https://doi.org/10.1016/j. carbpol.2015.08.035

Nelson ML, O'Connor RT (1964) Relation of certain infrared bands to cellulose crystallinity and crystal lattice type Part. II. A new infrared ratio for estimation of crystallinity in celluloses I and II. J Appl Polym Sci 8(3):1325-1341. https://doi.org/10.1002/app.1964.070080323

Nypelö T, Amer H, Konnerth J, Potthast A, Rosenau T (2018) Selfstanding nanocellulose Janus-Type films with aldehyde and carboxyl functionalities. Biomacromolecules 19(3):973-979. https://doi.org/10.1021/acs.biomac.7b01751

Nypelö T, Berke B, Spirk S, Sirviö JA (2021) Review: Periodate oxidation of wood polysaccharides-Modulation of hierarchies. Carbohydr Polym 252(117):105. https://doi.org/10. 1016/j.carbpol.2020.117105

Palme A, Idström A, Nordstierna L, Brelid H (2014) Chemical and ultrastructural changes in cotton cellulose induced by laundering and textile use. Cellulose 21(6):4681-4691. https://doi.org/10.1007/s10570-014-0434-9

Park S, Baker JO, Himmel ME, Parilla PA, Johnson DK (2010) Cellulose crystallinity index: measurement techniques and their impact on interpreting cellulase performance. Biotechnol Biofuels 3(1):10. https://doi.org/10.1186/1754-6834-3-10

Plappert SF, Quraishi S, Pircher N, Mikkonen KS, Veigel S, Klinger KM, Potthast A, Rosenau T, Liebner FW (2018) Transparent, flexible, and strong 2,3-dialdehyde cellulose films with high oxygen barrier properties. Biomacromolecules 19(7):2969-2978. https://doi.org/10.1021/acs. biomac. 8 b00536

Potthast A, Kostic M, Schiehser S, Kosma P, Rosenau T (2007) Studies on oxidative modifications of cellulose in the periodate system: molecular weight distribution and carbonyl group profiles. Holzforschung 61(6):662-667. https://doi.org/10.1515/HF.2007.099

Potthast A, Schiehser S, Rosenau T, Kostic M (2009) Oxidative modifications of cellulose in the periodate system-Reduction and beta-elimination reactions: 2nd ICC 2007, Tokyo, Japan, October 25-29, 2007. Holzforschung 63(1):12-17. https://doi.org/10.1515/HF.2009.108

Siller M, Amer H, Bacher M, Roggenstein W, Rosenau T, Potthast A (2015) Effects of periodate oxidation on cellulose polymorphs. Cellulose 22(4):2245-2261. https://doi. org/10.1007/s10570-015-0648-5

Sinha A, Martin EM, Lim KT, Carrier DJ, Han H, Zharov VP, Kim JW (2015) Cellulose nanocrystals as advanced "Green" Materials for Biological and Biomedical Engineering. J Biosyst Eng 40(4):373-393. https://doi.org/10. 5307/JBE.2015.40.4.373

Sulaeva I, Klinger KM, Amer H, Henniges U, Rosenau T, Potthast A (2015) Determination of molar mass distributions of highly oxidized dialdehyde cellulose by size exclusion chromatography and asymmetric flow field-flow fractionation. Cellulose 22(6):3569-3581. https://doi.org/ 10.1007/s10570-015-0769-x

Sun B, Hou Q, Liu Z, Ni Y (2015) Sodium periodate oxidation of cellulose nanocrystal and its application as a paper wet strength additive. Cellulose 22(2):1135-1146. https://doi. org/10.1007/s10570-015-0575-5 
Vanderfleet OM, Cranston ED (2021) Production routes to tailor the performance of cellulose nanocrystals. Nat Rev Mater 6(2):124-144. https://doi.org/10.1038/s41578-020-00239-y

Yuldoshov S, Atakhanov A, Rashidova S (2016) Cotton cellulose, microcrystalline cellulose and nanocellulose: carboxymethylation and oxidation reaction activity. J Nanosci Nanotechnol 10(6):106

Zhao H, Heindel ND (1991) Determination of degree of substitution of formyl groups in Polyaldehyde Dextran by the hydroxylamine hydrochloride method. Pharmaceut Res 8:400-402. https://doi.org/10.1023/A:1015866104055

Zoppe JO, Larsson PA, Cusola O (2020) Surface modification of nanocellulosics and functionalities. In: Lignocellulosics, Elsevier, pp 17-63

Publisher's Note Springer Nature remains neutral with regard to jurisdictional claims in published maps and institutional affiliations. 